\title{
The Support of Port Regulation Creation and Update by Real-time Ship Manoeuvring Simulation Studies Exampled by Port of Kolobrzeg
}

\author{
L. Gucma \& K. Łazuga \\ Maritime University of Szczecin, Szczecin, Poland
}

\begin{abstract}
The port areas are specific in terms of navigational accidents. Usually, accidents with low consequences dominate, but due to many users with contradictory needs, there is a requirement to keep the balance between business and safety. This balance is usually achieved by the Port Authority or like in Poland by Maritime Office together with Port Authority. Maritime Offices are the governmental body responsible to maintain the acceptable navigational safety level. Such an approach leads to several frictions between the users that needs are often contradictory. To ensure minimal safety level and introduce new or amended port regulations the scientific methods are demanded to support this process. The paper present methodology to adjust the port regulations of Kołobrzeg Port where the passenger ship owners moored in close vicinity of the waterway and therefore restricted it to the other users. The compromise was achieved with the application of real-time simulation method. Moreover, the paper presents the important role of harbor regulations in whole navigation risk management process within the port area. Today's port regulations are created mostly based on good practice of pilots and experts, whereas the quantitative methods are used less frequently. The intention of the presented case study was to demonstrate how the quantitative risk assessment could be used in port policy development.
\end{abstract}

\section{INTRODUCTION}

Ports, due to their nature of business activity and complexity are highly challenging in the development and implementation of the port regulations that should be in line with Port Safety Management System (PSMS). Moreover, the interests of groups with opposite goals are frequently encountered in ports. The crucial role is played here by the Harbour Master (in Poland acting under the Maritime Office), who is responsible for overall port safety, implementation of safety regulations and PSMS, information exchange, environment monitoring and information and security inside the ports. Unfortunately, there is a lack of global regulation in this area. There are several attempts and case studies to create such regulations [Billington 2001] but there are serious obstructions in particular because such a framework must satisfy global, regional, local, and industry regulations, which are sometimes almost impossible.

The most comprehensive and described legal framework for PSMS is UK Port Marine Safety Code [Port Marine Safety Code, 2012] introducing a formal risk assessment including the ALARP concept. The similar comprehensive concept has been implemented in New Zealand and is applied in other countries like U.S., Canada or Netherlands. The risk management procedure applied according to the above standard is based on the several steps like:

1 Data Gathering and Familiarisation; 
2 Hazard Identification;

3 Risk Analysis;

4 Risk Assessment;

5 Risk Control.

The port regulations (port bye-laws) has the significant role in safety management process as a major implementer of Risk Control Options (RCO). Additionally, to port regulations, several documents exists in ports like:

1 terminal safety procedures,

2 terminal operational procedures,

3 procedures of accidents consequences mitigation (such as contingency planning).

Port regulations are often created based on expert opinions (pilots, users, Harbour Master) using specific local knowledge. The dangerous cargo terminals (oil, gas or chemical) usually operates under international industrial legal framework created by organizations such as OCIMF (Oil Companies International Marine Forum) or ICS (International Chamber of Shipping). The accidents with significant consequences in port areas are rare events, which could create problems in creating proper methodologies of its analysis and could be the reason of poor policy decisions [Gucma 2009]. The risk assessment in port areas is a process where all possible hazards should be taken into account and finally summed up [Harrald et al, 1992] and [Trbojevic and Carr 2000].

The studies made by Pearson, Kuzmin, and Clouter [Pearson, Kuzmin, and Clouter 2015] show that port infrastructure facilities significantly affect vessel exposure to the risk. Also, studies made by Wang and Foinikis [Wang and Foinikis 2001] and earlier one, made by Zec, Zorovic, and Vranic [Zec, Zorović, and Vranić 1998] stressed this problem and reveals that FSA methodology could fail in relation to constantly changing port infrastructure. Moreover, authors claim and show in this paper that the problem has complicated spatiotemporal nature due to variability in quay occupation.

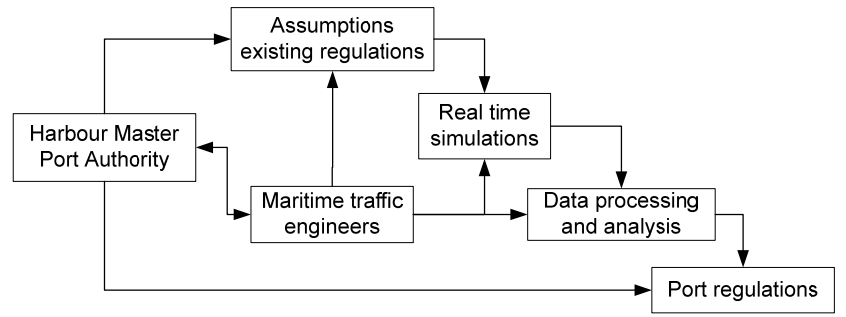

Figure 1. General method applied in study

In the presented study, the real simulation method has been introduced to find the potential risk of striking to the moored ships by passing ships due to navigational process failure. The problem with the decreasing safety level of entering ships due to moored ships are frequent in port areas since many opposite needs of users are encounter here. Usually the berths have predefined maximal breadth of ships that can be moored safely not influenced negatively the ships traffic in the vicinity. Such value could be also included in the port regulations. The aim of the presented method is to give the decision makers framework methodology of calculating the risk with possible actions that should be taken to minimize it to the acceptable level (Fig. 1).
The researches described in this paper are focused on updating and adjusting to new users the harbour regulations in Port of Kołobrzeg by real time simulation method with assuring minimum level of navigational safety [Determination 2016]. The main aim of researches was concerned with [PIANC 2014]:

1 Determination of:

- safety waterways parameters needed for safe operation of investigated ships,

- turning place diameter with respect to its shape and depth;

2 Determination of safety conditions of port operation in respect to:

- admissible meteorological conditions for given kind of ships and manoeuvres;

- other navigational conditions and limitations like presence of other ships on berths, use of position fixing systems on approach, navigational markings, vessel traffic service.

3 Determination of manoeuvring procedures during berthing and unberthing for different kind of ships and propulsion systems.

Kołobrzeg Port (Fig. 2) is a medium polish port located on the Baltic Sea serving over 100 merchant ships per year with fishing and pleasure craft traffic. Maximal length of ships before presented researches was $L=85 \mathrm{~m}$ with several operational and weather restrictions.

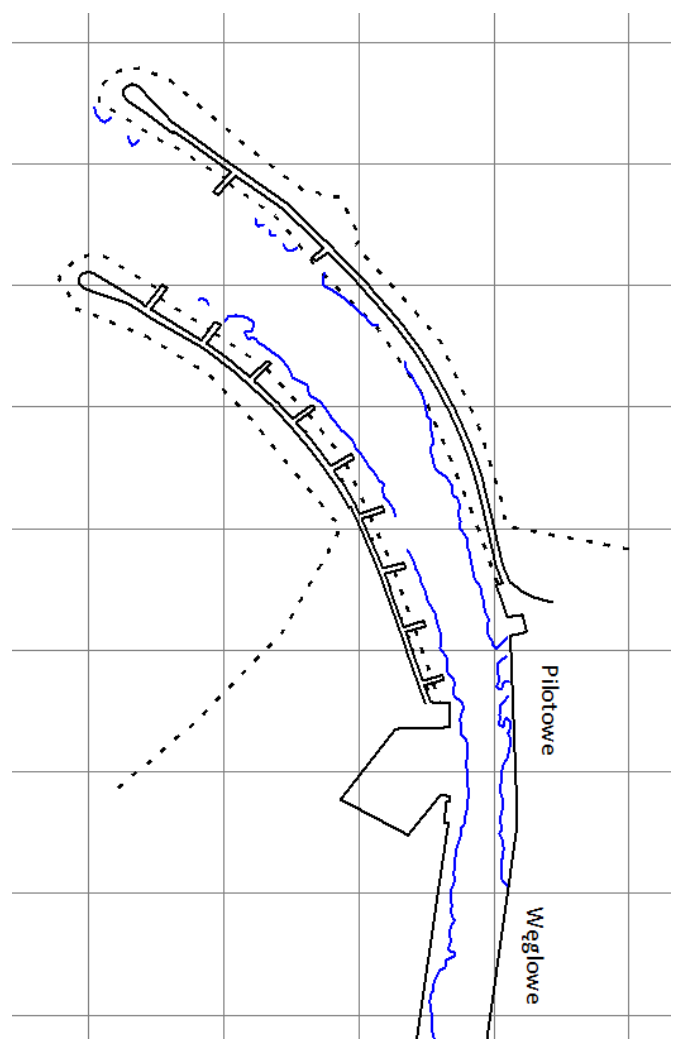

Figure 2. Kołobrzeg Port entrance and north inner channel with localisation of Pilotowe and Węglowe Quays.

As a design ship (named in this study as as $\mathrm{m} / \mathrm{s}$ Kotmax) is the general cargo ship of $100 \mathrm{~m}$ length. The ship was selected according to port economic analysis and their needs as the typical Baltic Sea coaster. The essential parameters of design ship are presented in the Tab. 1. 
Table 1. Main parameters of design coaster operated on the Baltic Sea area [Determination 2016]

\begin{tabular}{ll}
\hline Parameter & $\mathrm{m} / \mathrm{f}$ Kołmax \\
\hline Length - LOA & $100 \mathrm{~m}$ \\
Breadth - B & $15.0 \mathrm{~m}$ \\
Draft - T & $5.0 \mathrm{~m}$ \\
Engine power & $2,700 \mathrm{~kW}$ \\
Propeller & fixed pitch propeller, right handed \\
Speed & approx. $11 \mathrm{kn}$. at $90 \%$ \\
Bowthruster & 250kW \\
\hline
\end{tabular}

\section{THE PORT REGULATION CHANGE AS THE TRIGGER TO THE PRESENTED RESEARCHES}

The major trigger of presented researches was contradictory needs of two port user groups. From one side during the summer there is high passenger traffic and from the other the typical merchant traffic exist in the port. Passenger ships tends to berth close to the waterway and on the waterway bend, therefore pilots and captains of large ships entering the port complained and informed the Harbour Authority that safety could be threatened. The main aim of researches was finding the compromise between those two user groups. Therefore, the major research question was related with the number and size of ships that can be moored to Węglowe and Pilotowe Quays (Fig. 3). Additionally the conditions when safe operations could be realised will be defined. Typically, in high season there are 3 ships of $\mathrm{m} / \mathrm{f}$ Monika type $(L=26 \mathrm{~m}, B=6.5 \mathrm{~m})$ and one catamaran of $\mathrm{m} / \mathrm{f}$ Jantar type $(L=38, B=11,5 \mathrm{~m})$.

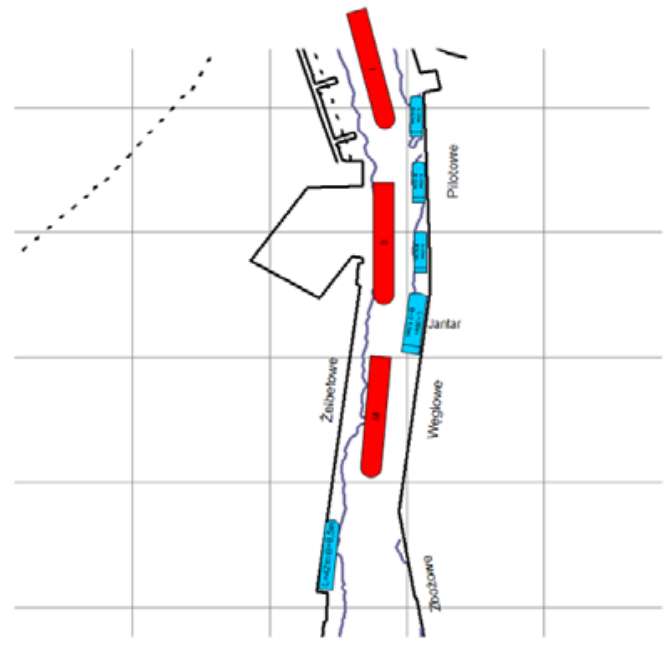

Figure 3. The localisation of moored ships [Computer simulation 2012].

\section{REAL TIME MANOEUVRING SIMULATION METHOD - LIMITED TASK SIMULATOR}

The real time simulation interactive method with captains and pilots engaged in ships manoeuvring trials was applied. This method is assumed as most reliable and suitable in this kind of research studies [Gucma 2013]. The so-called limited task simulator with 2D display was utilized in the researches. The simulator is made and owned by Maritime University of Szczecin [Gucma 2013]. The hydrodynamic models used in this simulator is based on detailed and exact characteristics parameters of hulls, propellers and steering devices are known. Additionally real manoeuvring characteristics are used for validation of models. The model of $\mathrm{m} / \mathrm{f}$ Kotmax used in researches is based on modular methodology where all influences like hull hydrodynamic forces, propeller drag and steering equipment forces and given external influences are modelled as separate forces and at the end summed as perpendicular, parallel and rotational ones [Artyszuk 2005].

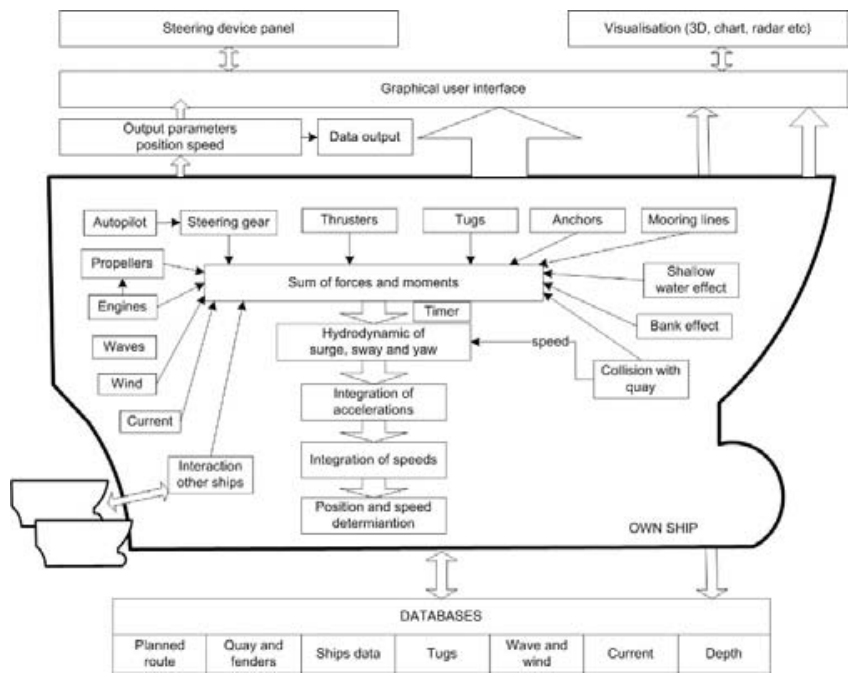

Figure 4. The main functional diagram of simulation model applied in this study.

The functional idea of the ship manoeuvring simulation model is presented in Fig. 4. Interface of model is typical 2D nautical chart - like interface (Fig. 5). The interface covers information of ships state (position, course speed, yaw etc), quay and shoreline location, navigational markings, soundings, external conditions, tug, and line control and control elements of the model. The model is implemented in Object Pascal with use of Delphi ${ }^{\mathrm{TM}}$ environment and Visual $\mathrm{C}^{\mathrm{TM}}$ with use of $\mathrm{C}++$ language. Limiting to the usual 3DOFs (the horizontal planar motion), the ship movement over the ground (thus the so-called dynamic effect of the water current is introduced) is given by Artyszuk [Artyszuk 2005]. The most important here is verification of ships hydrodynamic model. Usually the process is made to achieve less than $10 \%$ error between model and real ship in selected trials like turning trial, zig-zag and stopping acceleration. 


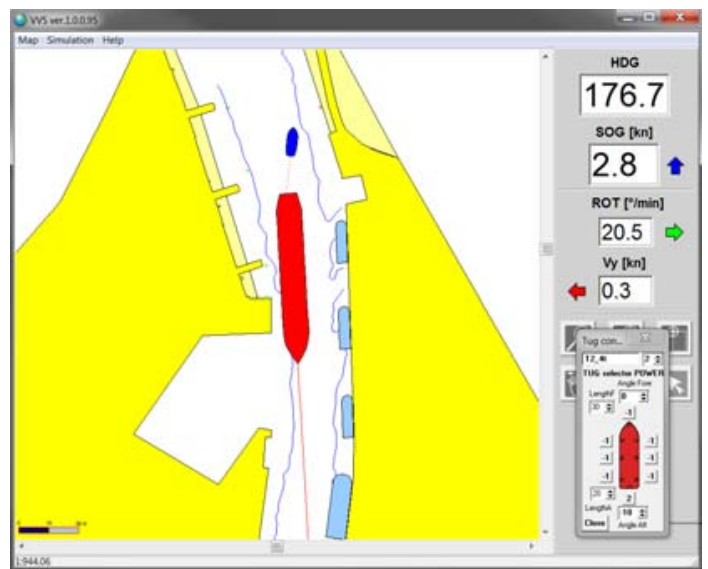

Figure 5. The GUI of simulation model (tug control pane activated).

\section{STATISTICAL METHODS OF DATA PROCESSING}

Ship real time simulators are very widely used today especially for training purposes. The hydrodynamic models are becoming more and more reliable. Without efficient statistical data processing, it is not possible to draw proper conclusions from the conducted experiments. Usually different kind of data processing analysis is applied in case when horizontal and vertical ships movement is considered.

\subsection{Safe manoeuvring areas - method of simulation result data processing}

The most important factor is safety horizontal area needed for navigators for performing manoeuvres [Gucma 2013, Irribaren 1999]. In single series of simulation trials, the several ships paths (twodimensional area, which occupies the ship in a single passage) can be obtained which depends on the number of performed experiments. Statistical processing of the simulation results allows determining the statistical parameters necessary to determine the safe manoeuvring area (SMA).

The characteristic values for the examined waterway are areas occupied by ships determined at the level of (Fig. 6):

1 maximum (extreme ships positions in all trials),

2 average (defined as mean SMA),

3 on given confidence level (defined as SMA).

Analysis of simulations results, leads to determination of horizontal safe manoeuvring area parameters. In simulation tests, these parameters are determined based on width of the ship's traffic lane, which is the area occupied by a single, ship during performing specific manoeuvre. Traffic lane (so called PATH) is defined for given, specific ship and manoeuvre, whereas safe manoeuvring area (SMA) is a term given to the different ships and manoeuvres (Fig. 6). In the Fig. 6 it is shown that safe manoeuvring area exceeds available water area (AWA) what results in necessity of introducing some changes (like dredging works) to avoid accidents.

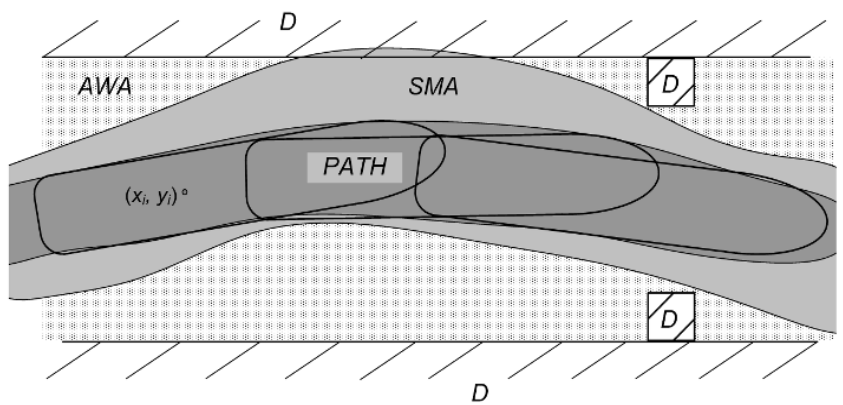

Figure 6. Definition of the ideas connected with horizontal areas taken by ships (PATH - lane of single ship, AWA available water area, SMA - safe manoeuvre area on the required confidence level, $\mathrm{D}$ - navigational danger)

Safe manoeuvring area is the area in which the probability of collision of the ship with the edge and/or the bottom, is on the assumed, high level. In the polish maritime waterway studies, usually $95 \%$ is applied in typical operations and $99 \%$ in more critical operations such as in presence of passengers of dangerous cargo [Gucma 2009]. Condition of safe navigation shall fulfil dependency:

$d_{i \alpha} \leq D_{i}$

where:

$D_{i}$ - width $i$-th point of the waterway at the bottom for safe depth,

$d_{i \alpha}-$ width of safe manoeuvring area on defined confidence level $(1-\alpha)$.

It should be noticed that general population with infinite number are all possible simulation trials of particular ship on the water area at the same hydrometeorological conditions. Whereas, sample will be the series of simulation trials conducted appropriate number of times at the same conditions. The width of the safe manoeuvring area of the ship is the range, which contain specified as a percentage part (fraction) of the population general. It can be defined accordingly to dependency that takes advantage with range of confidence term:

$d_{i \alpha}=m_{d i}+k_{\alpha} \sigma_{p i}+k_{\alpha} \sigma_{l i}$

where:

$m_{d i}=m_{p i}-m_{l i}$

or according to equivalent dependence in the form of:

$d_{i \alpha}=d_{i p \alpha}-d_{i l \alpha}$

for:

$d_{i p \alpha}=m_{p i}+k_{\alpha} \sigma_{p i}$ and $d_{i l \alpha}=m_{l i}-k_{\alpha} \sigma_{l i}$

where:

$d_{i \alpha}-$ width of the safe manoeuvring area at $i$-th point of the waterway defined on the confidence level $(1-\alpha)$;

$m_{d i}$ - mean of the safe manoeuvring area width; $k_{\alpha}$ - factor dependent on fraction of general 
population $p$, which should be taken into estimation (for SMA 95\% assumed as $k=1,96$ );

$m_{l i}, m_{p i}-$ mean from maximum distance of ship's points to the left from $i$-th point of the waterway;

$\sigma i, \sigma_{p i}$-standard deviations of maximum distance of ship's points to the left from $i$-th point of the waterway;

$d_{i l \alpha}, d_{i p \alpha}$-width of the right and the left safe manoeuvre area at $i$-th point of the waterway at defined confidence level $(1-\alpha)$.

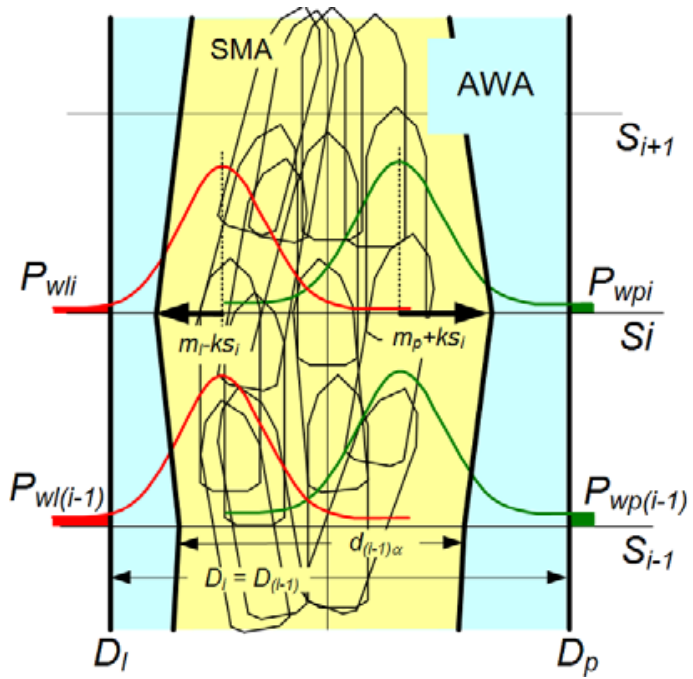

Figure 7. Probabilistic method of defining the safe manoeuvre area (SMA) and the probability of ship outside the available water area (AWA)

\section{RESEARCH PLAN AND RESEARCHES}

The following four simulation series have been planned and then conducted as representative to the research problem:

1 zero wind conditions - for validation and comparing of manoeuvring areas;

2 entrance to the port with wind $\mathrm{W} 10 \mathrm{~m} / \mathrm{s}$;

3 entrance to the port with wind E $10 \mathrm{~m} / \mathrm{s}$;

4 departure from port with wind W $10 \mathrm{~m} / \mathrm{s}$.

Current speed of the Parsęta River was modelled as typical of mean value $1 \mathrm{kn}$ outbound. Wave effects was neglected. In all series the moored ships was presented but they were modelled as "soft" which means that ships model could move over the moored ship without the effect of collision. This gives opportunity to analyse also the passages when the collision occurs. The captains performing simulations were informed about this and asked to avoid as much as they can to "sail over" moored ships. In total 5 experiences captains and one pilot were performing the simulations. The 17 ship passages were performed for each simulation series, which make 68 simulation runs in total (Fig. 8).

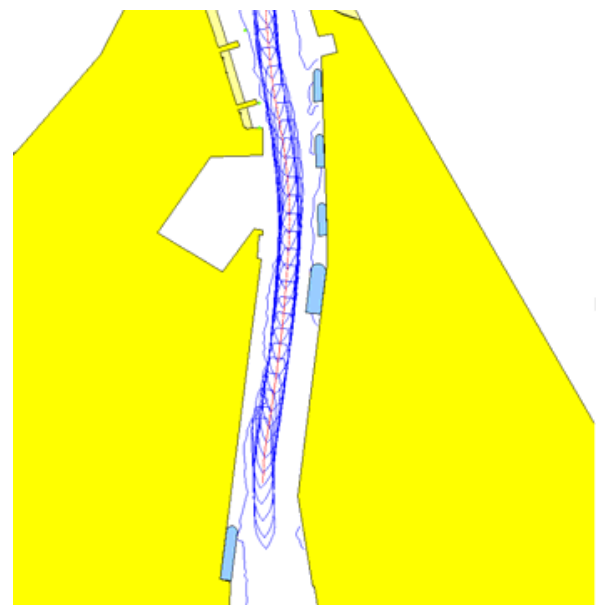

Figure 8. The single simulation passage of entering ship in presence of moored ships.

\section{RESULTS OF SIMULATION RESEARCHES}

All the simulation trials have been conducted by skilled captains and pilots having experience in this kind of ships and manoeuvres. The simulation data have been recorded and analysed. Analysis of simulation results was made in basis of one criterion: horizontal safe manoeuvring area dimension on $95 \%$ level of confidence as typically used in maritime operations [Gucma 2009, R0M 3.1-99. 2007]. The results from four aggregated series are presented in Fig. 9.

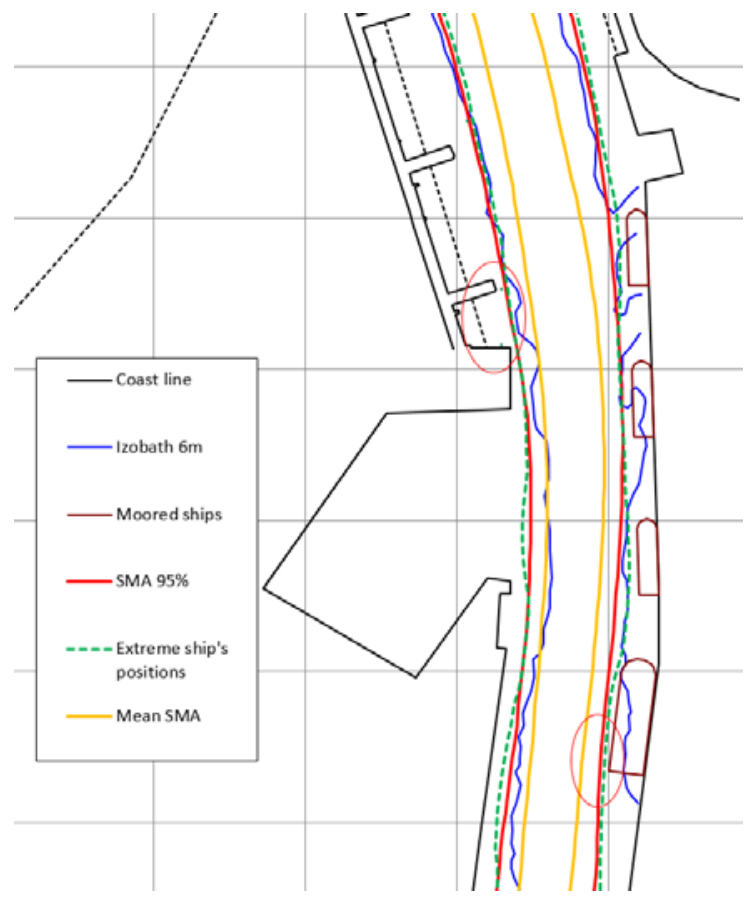

Figure 9. Manoeuvring areas of four cumulative series (68 passages of $\mathrm{m} / \mathrm{f}$ Kotmax) during entrance and departure from Kołobrzeg. 
Table 2. Selected parameters of manoeuvring areas for 3 chosen sections of the waterway with moored ships (values in meters)

\begin{tabular}{|c|c|c|c|c|c|}
\hline \multirow[t]{2}{*}{ Series } & \multirow{2}{*}{$\begin{array}{l}\text { Parametr } \\
\text { / Quay }\end{array}$} & \multirow{2}{*}{$\begin{array}{l}\text { Pilotowe } \\
\text { N }\end{array}$} & \multirow{2}{*}{$\begin{array}{l}\text { Mid. I } \\
\text { Pilotowe }\end{array}$} & Pilotowe & \multirow{2}{*}{$\begin{array}{l}\text { Węglow } \\
\text { N }\end{array}$} \\
\hline & & & & $S$ & \\
\hline \multicolumn{6}{|c|}{ Series 2} \\
\hline width & f SMA 95\% & 41.5 & 35.5 & 31 & 30 \\
\hline width & f mean SMA & 24 & 22.6 & 20.3 & 18.7 \\
\hline $\begin{array}{l}\text { standa } \\
\text { Series }\end{array}$ & d deviation SMA & 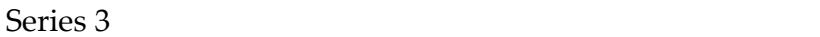 & 3.3 & 2.7 & 2.8 \\
\hline width & f SMA 95\% & 42 & 34.5 & 31 & 30 \\
\hline widt & f mean SMA & 23.9 & 22.6 & 20.5 & 18.7 \\
\hline \multicolumn{5}{|c|}{ Series 4} & 2.8 \\
\hline width & f SMA 95\% & 39 & 35.5 & 33.9 & 32.3 \\
\hline widt & f mean SMA & 22.4 & 21.8 & 20.2 & 19.7 \\
\hline standa & d deviation SMA & 4 & 3.7 & 3.1 & 3 \\
\hline
\end{tabular}

The parameters from Tab. 2 was used to determine the safe future waterway parameters for ships of $L=100 \mathrm{~m}$ that can be operated in presence of moored ships. The confidence level for waterway model was set as $95 \%$ confidence interval but the waterway was shifted away of the moored biggest ship (m/f Jantar) for the distance guarantee $99 \%$ of probability of safe operation. The following formula was used to determine the distance from waterway limits to moored ship based on confidence intervals:

$d_{m}=\left(k_{99 \%}-k_{95 \%}\right) s=(3.29-1.96) s \cong 5 m$

where:

$d_{m}$ - distance from model waterway to moored ship,

$s-$ standard deviation of normal distribution of ships positions determined in simulations,

$k 99 \%$ - confidence intervals for normal distribution for $99 \%$.

As the result of above calculation and some approximations, the model of safe waterway was created (Fig. 10). The presented model waterway is one of the major outputs from the study, since it shows how in the future the waterway shall be implemented.

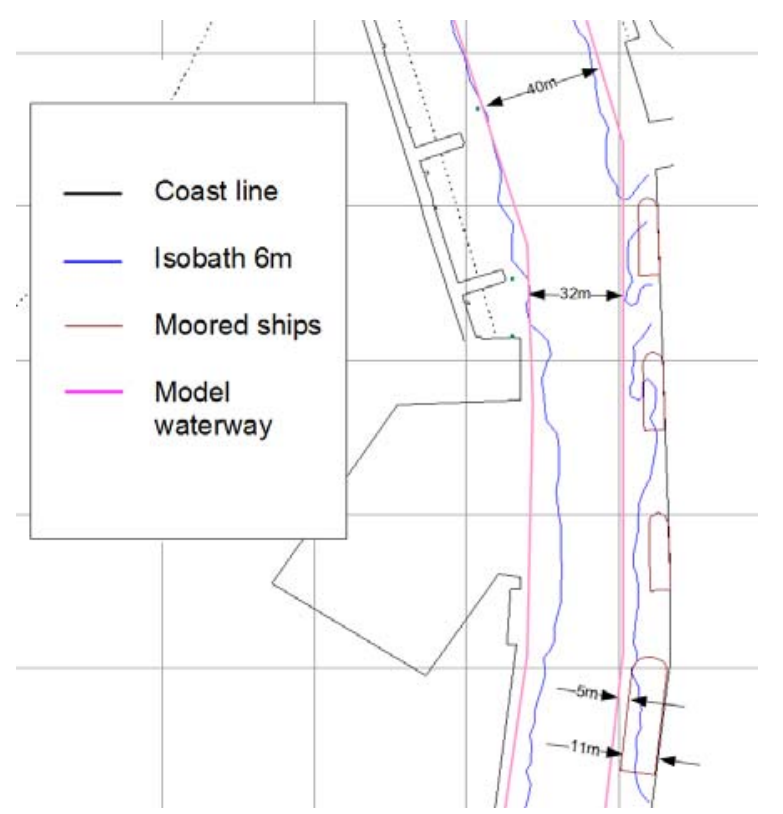

Figure 10. Suggested parameters of new waterway to fulfil all the needs of port users

\section{CONCLUSIONS}

Presented study showed the potential usability of real time simulation methods for creation and adjusting of the port regulations in quantitative way. Moreover, such method could be used to solve conflicts between user groups arising in port areas in objective way with use of the real time simulation method. The real time simulation method and applied here limited task simulator proved its usability in port regulation creation to increase the cost of port operations without reducing the navigational safety level. Some precautions shall be taken into account like for example:

- Simulators are widely used tools but verification shall be made on the beginning covered especially the simulation hydrodynamic model and hydrometeorological conditions to adjust them as much as possible to the reality.

- The simulation method is often used as so called "single ship passage study" so the results are based on single or very small group of simulations without statistical data processing and without the plan of experiments. Such approach is not acceptable and the results achieved in such way, even by sophisticated models, are questionable.

- Very good link shall be established between pilots with good local knowledge for validation and as local knowledge foundation.

- So-called Super Captain (the person who knows very well simulator and its limitations and has significant knowledge about ship manoeuvring) shall be asked for final validation of all simulation setup.

The presented study delivered several detailed results formulated as conclusions (more than 15 detailed conclusions were drawn), which were given to the Harbour Authority to include them after legislation changes incorporated to the port regulations. Such detailed remarks were for example:

1 It is possible to enter ships of length up to $L=90 \mathrm{~m}$ and width up to $B=12 \mathrm{~m}$ (both parameters must be fulfilled at the same time) with moored ships of breadth up to $\mathrm{B}=6.5 \mathrm{~m}$ (m/f Monika type) on Pilotowe Quay and moored $\mathrm{m} / \mathrm{f}$ Jantar (breadth equal to $B=11.5 \mathrm{~m}$ ) with wind up to $10 \mathrm{~m} / \mathrm{s}$ from any direction.

2 It is possible to enter units of length up to $\mathrm{L}=100 \mathrm{~m}$ and width up to $B=13 \mathrm{~m}$ (both parameters must be fulfilled at the same time) with moored ship of $\mathrm{m} / \mathrm{f}$ Monika type at Pilotowe Quay and moored $\mathrm{m} / \mathrm{f}$ Jantar in good weather conditions, i.e. with wind up to $4^{\circ} \mathrm{B}(8 \mathrm{~m} / \mathrm{s})$ from any direction.

It should be noted that formulation of such conclusions derived from simulation researches should be made in special clear language with some legislation background mainly to:

1 cover all possible ship sizes,

2 cover all possible meteorological conditions,

3 cover all possible operational situations,

4 be logically consistent and understand,

5 must not contain inconsistent and contradictory statements. 


\section{REFERENCES}

Artyszuk J. 2005. Towards a Scaled Manoeuvring Mathematical Model for a Ship of Arbitrary Size. Scientific Bulletin no6, Maritime University of Szczecin.

Billington C.J. 2001. Managing risks in ports. Managing Risks in Shipping: A Practical Guide. London: The Nautical Institute, 2001, 57-69.

Determination 2016. Determination of maximum ships, which may be operated in the port of Kotobrzeg, taking into account possible simulation methods of port reconstructing. (in polish). Unpublished report. Maritime University of Szczecin.

Gucma L. (ed.) 2013 LNG terminals design and operation. Navigational safety aspects. Marine Traffic Engineering. Szczecin: 1-268, 2013

Gucma L. 2009. Maritime risk management. (in polish). Maritime University of Szczecin Press. Szczecin. 2009.

Harrald J.R., Mazzuchi TA and Stone Ch.M. 1992. Risky Business: Can We Believe Port Risk assessments? Proceedings of the Conference: Ports '92 (ed. Torseth D.), Seattle, USA, 20-22 July 1992, 657-669.
Iribarren J.R. 1999. Determining the horizontal dimensions of ship manoeuvring areas. PIANC Bulletin No 100, Bruxelles.

Pearson J, Kuzmin V. and Clouter E. 2015. Application of FSA in Polar Transportation. IAMU published research project.

PIANC. 2014. Harbour Approach Channels Design Guidelines. PIANC Report PIANC Secretariat General. Bruksela.

Port Marine Safety Code. 2012. Department for Transport and Maritime and Coastguard Agency. Amended Nov. 2016.

R0M 3.1-99. 2007. Recommendations for the Design of the Maritime Configuration of Ports, Approach Channels and Harbour Basins. Puertos del Estado.

Trbojevic V. and Carr B. 2000. Risk based methodology for safety improvement in ports. Journal of Hazardous Material 2000; 71: 467-480.

Wang J and Foinikis P. 2001. Formal Safety Assessment for Containership. Maritime Policy 2001; 25: 143-157.

Zec D, Zorović D. and Vranić D. 1998. Impact of the Formal Safety Assessment on Shipboard Operations. Scientific Journal on Traffic and Transportation Research 1998. 10 (3): 127-130. 